Brit. J. industr. Med., 1963, 20, 204.

\title{
STUDIES OF VENTILATORY CAPACITY AND HISTAMINE RESPONSE DURING EXPOSURE TO ISOCYANATE VAPOUR IN POLYURETHANE FOAM MANUFACTURE
}

\author{
BY \\ BRYAN GANDEVIA* \\ From the University Department of Medicine, Royal Melbourne Hospital, Victoria, Australia
}

(RECEIVED FOR PUBLICATION OCTOBER 24, 1962)

\begin{abstract}
Complaints of respiratory symptoms amongst workers in a factory using isocyanate to produce polyurethane foam led to a study of changes in ventilatory capacity in the course of several working days. Mean decreases of the order of 0.181 . were observed in the forced expiratory volume at one second in 15 employees during each of three normal working shifts. No significant change occurred on days when a process involving the liberation of isocyanate was stopped, or when the men were given an oral aminophylline compound prophylactically. An aerosol of isoprenaline failed to reverse the decrease in ventilatory capacity observed during one normal working day. Approximately half the subjects studied were found to show increased bronchial sensitivity to a histamine aerosol; all were smokers, whereas none of the non-smokers showed a significant (over $10 \%$ ) reduction in ventilatory capacity after histamine. Smokers and/or positive histamine reactors tended to show a greater decrease in ventilatory capacity during a working day than non-smokers or non-reactors. The present findings, which confirm clinical reports of adverse respiratory effects of isocyanate in low concentrations, are compared with other studies of ventilatory capacity during occupational exposure to respiratory irritants.
\end{abstract}

Isocyanate vapour liberated during the production of a variety of plastic materials has been recognized as the cause of a syndrome resembling asthma and bronchitis in men (Fuchs and Valade, 1951; Reinl, 1953; Holmqvist, Lundgren and Swensson, 1953; Swensson, Holmqvist and Lundgren, 1955; Walworth and Virchow, 1959) and as productive of more severe and irreversible bronchopulmonary damage in animals under appropriate conditions (Friebel and Lüchtrath, 1955; Zapp, 1957). Its local toxicity is indicated by the suggested maximum permissible concentration of 0.1 part per million, below which symptoms were not observed in exposed workers (Sands, Boffardi, James, Lundy, and Walsh, 1957; Zapp, 1957).

Complaints of respiratory symptoms led to an investigation of workers in a small factory producing rigid polyurethane foam. This paper deals with the results of studies of ventilatory capacity on all employees under varying circumstances in the course of

*Ernest F. Atkins senior fellow in industrial medicine, University of Melbourne. Present address: Department of Medicine, University of New South Wales, Sydney, Australia. two weeks. The clinical and other aspects of the outbreak will be reviewed elsewhere (Gandevia, in preparation).

\section{The Factory and Production Methods}

The factory consists essentially of one large workroom about $7,000 \mathrm{ft}^{2}\left(650 \mathrm{~m}^{2}{ }^{2}\right)$ in area, with a roof height of $18 \mathrm{ft} .(5.5 \mathrm{~m}$.). In one corner, in the open, the "mix" is prepared by a semi-automatic process involving pouring of constituents into an open drum resting on scales. The two main components, both in liquid form, are (a) a quasi-polymer of toluene di-isocyanate and a polyol (tris-hydroxy propyl glycerol) with a $30 \%$ excess of isocyanate groupings, and $(b)$ a proprietary polyol with hydroxyl-rich branch chains. Small quantities of a solid catalyst, triethylene diamine, are added. The "blowing agent" is monofluorodichlormethane ("Freon 11"), which has a boiling point of $75^{\circ} \mathrm{F}$. $\left(24^{\circ} \mathrm{C}\right.$.); converted to gaseous form by the heat of polymerization reactions, this substance produces the "foam" in the finished product. 
Once a day, for $\mathbf{4 0}$ minutes, this mixture is pumped to a conveyor belt $5 \mathrm{ft}$. $(1.524 \mathrm{~m}$.) wide, at one end of which it is evenly distributed. Foaming begins 30 seconds after deposition and is substantially complete after one minute, by which time the belt has travelled about $6 \mathrm{ft}$. $(1.828 \mathrm{~m}$.) and the original thick film has risen to a height of about 18 in. $(45.72 \mathrm{~cm}$.). It is in this period that gaseous liberation, notably of isocyanate, is likely to occur. Subsequently polymerization continues more slowly whilst the material is in the solid phase. About $1,800 \mathrm{lb}$. $(816.466 \mathrm{~kg}$.), or 120 linear $\mathrm{ft}$. $(36.88 \mathrm{~m}$.), of the final product are prepared in the course of a single "run". No part of the mixing or foaming processes was enclosed at the time of the investigation, nor was there any specific ventilation. One large door, almost diagonally opposite the main process, and about $60 \mathrm{ft}$. (18.44 m.) away, provided the only important source of ventilation at this time.

The remainder of the floor space is largely devoted to storage except for four benches where saws of several types are used to cut the rigid foam to desired sizes. Microscopic examination of the "dust" so produced shows that the "honeycomb" consists of polyhedral "cells" approximately $200 \mu$ in diameter, the broken particles being considerably smaller. The dust settles rapidly and is not seen to float or form a cloud.

At irregular intervals, foam is also produced in small individual moulds, partly sealed. This subsidiary production line, situated along the wall beside the main process, operated for an average of less than half an hour a day at the time of the study, producing about $3 \mathrm{lb}$. $(1.36 \mathrm{~kg}$.) of the final product per minute. No special ventilation was provided.

While the mixture was being prepared or run, the men in the immediate vicinity wore respirators with cannisters of activated charcoal as adsorbent; this practice was not rigidly enforced and did not apply to workmen in more remote parts of the work-room.

\section{Personnel and Plan of Investigation}

At any one time, about 20 men, including the production manager and the foreman, were employed in the factory itself from $8 \mathrm{a} . \mathrm{m}$. to $4.30 \mathrm{p} . \mathrm{m}$. five days a week. Available data suggest that the labour turnover was high and that one of the factors in this was a relatively high incidence of respiratory symptoms. The 20 men employed during the two-week period of study had been with the firm for an average of 16 weeks, range one to 78 weeks, only two men having worked there for over a year.

The average age of the employees was 33.7 years, range 19 to 57 years. All the men, excluding one man who left the job before he was interviewed, gave a history of a normal exercise tolerance, and all but one (No. 18) denied cough and sputum in the mornings for more than three months of the year prior to their present employment.
None had a past history of asthma or wheezing. When asked by the examiner to cough, seven men were able to produce sputum. Four of these, and two others, had an audible wheeze on full but unhurried expiration. Recent chest radiographs were not available; all but three had had normal mass radiography films in the previous three years, and the remainder within the past seven years.

Measurements of ventilatory capacity were made at 8 a.m. and 4 p.m. on each of five days:-

Day 1. The first Monday, a normal working day

Day 2. The following Friday, a normal working day

Day 3. The second Monday. By arrangement, no "mix" was prepared or run throughout the day, so that atmospheric contamination after the week-end was theoretically at a minimum.

Day 4. The next day (Tuesday, but approximately comparable to an average Monday in view of the previous day's minimal exposure); a normal working day, but the men were given "Elixophylline" $\dagger, 45 \mathrm{ml}$. (containing theophylline $240 \mathrm{mg}$.), at $8.30 \mathrm{a} . \mathrm{m}$. and 1.15 p.m.

Day 5. The following Monday, a normal working day.

In the tables the day is indicated by the appropriate numeral, while the suffixes $A$ and $B$ are used to indicate morning and afternoon readings respectively.

The index of ventilatory capacity chosen was the forced expiratory volume at one second (F.E.V..$_{1}$ ). This was estimated in the conventional manner, with the subject seated, using a low resistance spirometer and kymograph. The F.E.V..$_{1}$ was read off the forced expiratory spirograms with a graduated transparent protractor. The highest value from three "satisfactory" tracings was recorded, "satisfactory" tracings being spirograms which were identical on inspection and free from visible artefacts or evidence of incomplete co-operation. Values for F.E.V.1 rarely differ by more than $5 \%$ under these circumstances, and it becomes of little importance whether the mean or the highest value is recorded. All gas volumes were corrected to body temperature saturated with water vapour.

Following the 4 p.m. examination, isoprenaline sulphate 1:1000 was given by aerosol for one minute (using a Wright nebulizer and compressed air) and spirography was repeated. On Wednesday and Thursday of the second week, the F.E.V.1 was measured in 14 men before and after one minute's inhalation of histamine base, $20 \mathrm{mg}$. $/ \mathrm{ml}$., using an efficient nebulizer with compressed air.

The statistical analysis relates to the data on 15 of the 20 men. Subjects 10 and 18 were excluded as they had symptoms of acute respiratory disease at the time of the study; both showed gross falls in F.E.V.1 of over a litre during day 1 . Their results are described more fully elsewhere. Subject 12 is excluded because he was absent from work on day 1; his subsequent results conformed exactly to the over-all pattern. Subject 19 left the job after day 1

†This preparation was chosen because it is supposed to produce minimal gastrointestinal side-effects in moderate dosage and because a fluid mixture taken under apparently casual observation cannot be disposed of by any means other than swallowing. Its alcohol content, although perhaps scientifically open to criticism, was a valuable selling point. The absorption and bronchodilator effect of the compound were regarded as established (for review, see Perlman, 1960; personal observations). 
for reasons unrelated to this investigation; his F.E.V.1 on this day fell from 3.46 to 3.381 . Subject 20 refused to cooperate after the morning of day 1 ; his initial F.E.V.1 was normal and the spirogram showed no evidence of airways obstruction. However, he had a history of a moderately severe respiratory illness six weeks previously, about two weeks after commencing work in the factory. He denied current cough and sputum, but a deliberate cough was productive. These observations suggest that he may have wished to conceal respiratory symptoms. Consideration of the five excluded cases indicates that such selection as exists is in the direction of selection of the fittest, especially when it is appreciated that at least a proportion of the high labour turnover may be attributed to the development of respiratory symptoms.

For the 15 subjects forming the basis of the present analysis the data are complete for days 1 and 2, at which time the employment of one man ceased. On day 5, two men were absent, one injured and one with a "cold", so that the number of available subjects was reduced to 12 . Other minor variations in the numbers are noted in the appropriate sections.

\section{Results}

Day-to-day Changes in Ventilatory Capacity.-The mean values for F.E.V..$_{1}$ on the mornings of days 1 to 5 inclusive are set out in Table 1 : the variations in the number of observations are determined by the losses of individuals described above.

The general trend is towards a decrease in ventilatory capacity over the period of observation. Comparison of the differences, using a paired $t$ test, between morning values for days 1 and 2 (Monday to Friday), days 1 and 3 , and 1 and 5 (three successive Mondays) is shown in Table 2. The mean falls in F.E.V. of $^{0.16} 1$. between days 1 and 2 , and of 0.231 . between days 1 and 5 are both highly significant. The decrease of $0 \cdot 141$. between days 1 and 3 does not reach the $5 \%$ level of significance, even if the data for all 14 available subjects on these days are used.

The mean decrease during one working week (days $1 \mathrm{~A}-2 \mathrm{~B})$ of 0.351 . is highly significant $(\mathrm{n}=15$, $\mathrm{t}=5.34 ; p<0.001$ ).

Changes in Ventilatory Capacity during the Day.Comparison of the morning and afternoon values for F.E.V.1 (Table 3) reveals statistically significant
TABLE 2

CHANGES IN F.E.V.1 (IN 12 SUBJECTS) BETWEEN THE FIRST MONDAY, THE FOLLOWING FRIDAY, AND THE TWO FOLLOWING MONDAYS: MORNING'VALUES

\begin{tabular}{l|c|c|c}
\hline & Days 1A-2A & Days 1A-3A & Days 1A-5A \\
\hline Mean change in F.E.V.1 & $\begin{array}{c}0.158 \\
3.34\end{array}$ & $\begin{array}{c}-0.140 \\
2.09\end{array}$ & $\begin{array}{c}-0.227 \\
2.92 \\
<.0 .02\end{array}$ \\
$t$ & $<0.01$ & $<0.1$ & $<0.02$ \\
\hline
\end{tabular}

TABLE 3

DIFFERENCES BETWEEN MORNING (A) AND AFTERNOON (B) VALUES FOR F.E.V.1

\begin{tabular}{|c|c|c|c|c|c|}
\hline & $\underset{1 A-B}{\text { Day }}$ & $\begin{array}{c}\text { Day } \\
2 A-B\end{array}$ & $\underset{\text { 3A-B }}{\text { Day }}$ & $\underset{\text { DA-B }}{\text { Day }}$ & $\underset{\text { SA-B }}{\text { Day }}$ \\
\hline Mean change & $-0 \cdot 182$ & $-0 \cdot 188$ & -0.100 & -0.013 & -0.140 \\
\hline $\begin{array}{l}\text { No. } \\
t \\
p\end{array}$ & $\begin{array}{c}15 \\
3.61 \\
<0.01\end{array}$ & $\begin{aligned} & 15 \\
& 2.81 \\
&< 0.02\end{aligned}$ & $\begin{aligned} & 14 \\
< & 1.58 \\
< & 0.2\end{aligned}$ & $\begin{array}{l}12 \\
0.28 \\
<0.8\end{array}$ & $\begin{array}{r}12 \\
2.59 \\
<0.05\end{array}$ \\
\hline
\end{tabular}

Days 1, 2 and 5 Normal working days

Day 3 Normal working day except that no mix was prepared

Day 4 Normal working day except Elixophylline given (see text)

decreases of the order of $0 \cdot 181$. on the three normal working days (days 1, 2, and 5). No significant fall occurred on the Monday on which no mix was prepared or run (day 3), or on the following day when a theophylline compound was given. The findings are the same when analysis is confined to the 12 subjects for whom the data are complete for all five days.

Two men on day 3 showed decreases in F.E.V.1 exceeding $10 \%$ of their morning values. Investigation revealed that one of the men had cleaned the pump and pipes used for the mix and had undoubtedly suffered significant exposure. To fulfil the project requirements, this process had been deferred until the extreme end of the day, when the others were ceasing work; the spirograms on this man were not taken until he had completed the job. The second man, questioned a week later, could recall no remarkable risk of exposure.

The results for day 4 relate to only 12 out of the 14 available men. One subject could not tolerate alcohol and therefore did not take the mixture: his F.E.V. ${ }_{1}$ over the day fell by 0.081 . The second man, overcome by an impelling urge for refreshment at the end of the day, had disappeared when his turn came

TABLE 1

DAY-TO-DAY CHANGES IN MEAN F.E.V.: MORNING VALUES

\begin{tabular}{|c|c|c|c|c|c|}
\hline Available No. of Men & Day $1 \mathrm{~A}$ & Day $2 A$ & Day 3A & Day $4 A$ & Day SA \\
\hline $\begin{array}{r}5 \\
14 \\
12\end{array}$ & $\begin{array}{l}4 \cdot 16(0.651) \\
4 \cdot 11(0.657) \\
4 \cdot 10(0.675)\end{array}$ & $\begin{array}{l}4.00(0.614) \\
3.94(0.594) \\
3.94(0.632)\end{array}$ & $\begin{array}{l}4.00 \overline{(0.686)} \\
3.96(0.684)\end{array}$ & $\begin{array}{l}3.85 \overline{(0.656)} \\
3.86(0.679)\end{array}$ & $3.87 \overline{(\dot{0} .656)}$ \\
\hline
\end{tabular}

Means in litres; standard deviation in parentheses 
for spirography. A third subject, whose F.E.V.1 fell by 0.071 ., did not take a full dose of the mixture at 1.15 p.m. because of nausea after the first dose; his results are included in the analysis.

Effect of Isoprenaline Aerosol.-The isoprenaline aerosol was given after the completion of the afternoon studies on day 2, that is, after the day $2 B$ estimations. The mean increase on the afternoon values for F.E.V..$_{1}$ in response to the aerosol was found to be $0 \cdot 141$. This difference fails to reach the $5 \%$ level of significance. In five cases there was a decrease in F.E.V.1, the greatest fall being 0.111 ; the remaining subjects showed a rise of from 0.02 to 0.811 ., only two increases exceeding $10 \%$ of the preaerosol values. Comparison of the morning and postaerosol values indicates no signicant difference $(\overline{\mathbf{x}}=$ $-0.05, t=0.073$ ) although, as seen in Table 3, the pre-aerosol afternoon values were significantly reduced on the morning estimations.

Although the aerosol may produce a trend towards a reversal of the drop during the current day, there is certainly less complete reversal of the week's decreases. Thus, on comparison of the morning results for day 1 with the post-aerosol results on day 2 , a statistically significant decrease of 0.231 . over the week remains in spite of the administration of isoprenaline $(\mathrm{n}=15 ; \mathrm{t}=5.12 ; p<0.001)$. No close relation was apparent between the magnitude of F.E.V. ${ }_{1}$ decreases during exposure and the response to the bronchodilator aerosol.

Effect of Aerosol of Histamine.-Twelve men were given the aerosol of histamine as described on days when no other measurements were being made. One man of the 13 available on the two days when this was done refused to co-operate; his F.E.V. ${ }_{1}$ showed a maximum daily variation of only 0.131 . in the five days of observations. Of the 12 tested, six showed a fall of F.E.V. 1 of more than $10 \%$, indicating a positive reaction: a smaller decrease was found in three men and a rise in three. The mean decrease was 0.44 1. Subject 10 , mentioned above as excluded because he developed acute respiratory symptoms with decreasing F.E.V.1 values during the study, was also tested; his F.E.V. 1 fell by $1 \cdot 121$., almost $50 \%$. Subject 12, otherwise omitted from the analysis because of absence on day 1 , also showed a positive reaction; his result on other days followed the changes in the means for the entire series. For the 14 subjects tested, the decreases in F.E.V. ${ }_{1}$ in reponse to histamine are plotted against the observed decreases in F.E.V..$_{1}$ at work, using the individual means for days 1 and 2 (Fig. 1); both decreases are plotted as percentages of the initial values. The relation is poor. However, the mean decrease in F.E.V.1 during

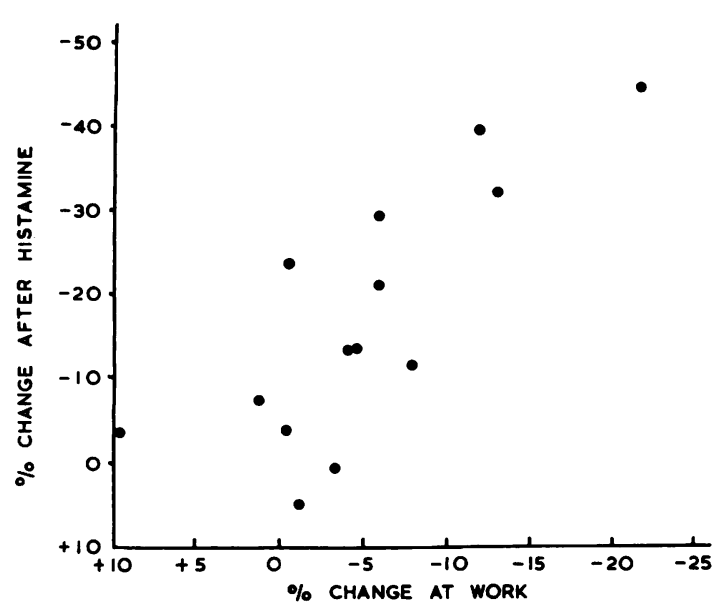

FIG. 1.-Decreases in F.E.V.1 in response to histamine plotted against observed decreases at work for 14 subjects.

working days of 0.311 . in the eight positive reactors to histamine is significant $(\mathrm{t}=\mathbf{4 . 2 8}, p<0.01)$; the mean decrease was only 0.1151 . in the non-reactors $(\mathrm{t}=1.69 ; p<0.2)$.

Effects of Smoking.- In the six non-smokers of the 15 men in the series for days 1 and 2, there was a mean decrease in F.E.V.1 of 0.1451 . $(t=2.86 ; p<0.05)$, whereas the decrease in the nine smokers averaged $0.211 .(t=3 \cdot 14 ; p<$ 0.02 ). The difference between these means is not significant. However, the most striking finding is in relation to bronchial sensitivity to histamine. All five non-smokers showed no significant response to the histamine aerosol: eight of the nine smokers formed the entire group of positive reactors. The probability that this was a chance finding is reasonably remote $\left(\mathrm{x}^{2}=7.06 ; p<0.01\right)$. The ninth smoker (20 cigarettes per day), with a negative response to histamine, was the only man in the whole series to show a slight rise in F.E.V..$_{1}$ on each of two normal working days. Four of the eight smoked 10 cigarettes or less a day (one smoked only five), the remainder smoking 20 or more a day.

\section{Discussion}

Day-to-day Variations.-The present findings indicate that significant decreases in ventilatory capacity occurred during the course of three normal working days but not on two days when either the main process was omitted or a theophylline compound was given orally. Recovery of ventilatory capacity did not occur overnight, for the Friday morning values were significantly lower than those of Monday. 
More disturbing is the suggestion that there may have been some cumulative effect over the period of the study, for ventilatory capacity on the third Monday was significantly lower than on the first. Radical changes in ventilation and methods of manufacture precluded further study of this point. Emphasis is given to these changes in ventilatory capacity by the fact that, although virtually the whole work force was studied, there was already probably a bias towards the selection of those with some "tolerance" to the materials used.

It is considered that the design of the investigation is such that these conclusions are justifiable on internal evidence. Nonetheless, it is of interest to review briefly other studies of variations in ventilatory capacity during the day or working week. No significant or consistent changes in ventilatory capacity occurred in a small personal series of hospital employees and patients during the day or between Mondays and Fridays; similar findings are recorded by others (Lewinsohn, Capel, and Smart, 1960; De Vries, Goei, Booy-Noord, and Orie, 1962). By contrast there is a tendency for patients with obstructive lung disease to show some rise between 9 a.m. and 4 p.m. (Lewinsohn et al., 1960; personal observations). An average rise has been noted during a shift in coal-miners (McKerrow, McDermott, Gilson, and Schilling, 1958), although in this group exercise may be a factor. Byssinotic subjects show significant daily decreases in F.E.V..$_{1}$ of the same order of magnitude as reported here(McKerrow et al., 1958; McKerrow and Schilling, 1961); the decrease is reduced or eliminated in the same subjects when not working in cotton dust and does not occur in workers in other, presumably less dusty, parts of the factory. The graphs in the paper by McKerrow et al. (1958) suggest that there is little difference in F.E.V. 1 between Monday and Thursday mornings, implying more effective overnight recovery than occurred in the isocyanate workers. Carey, G. C. R., Elwood, P. C., and Pemberton, J. (personal communication) found an average fall of $0.38 \pm$ 0.20 1. in F.E.V. . $_{1}$ between Monday and Thursday mornings in seven flax workers with respiratory symptoms; this finding, although statistically not significant, perhaps suggests that vegetable dusts, at least in subjects with symptoms on exposure, may produce, changes in ventilatory capacity of a longer duration than overnight. These workers also found a significant decrease in F.E.V..$_{1}$ on Mondays, but not on Thursdays, in the byssinotic subjects only. Other studies on a weekly basis appear to be lacking. No significant fall in ventilatory capacity occurred during the day in workers with rayon, including a group who had previously had symptoms of byssinosis whilst working in a cotton mill (Tiller and Schilling, 1958).
Gilson, Stott, Hopwood, Roach, McKerrow, and Schilling (1962) conclude that dust in jute and sisal mills is probably not associated with a decrease in ventilatory capacity, but we have observed a decrease when workers are exposed to heavy concentrations of grain dust for short periods (Gandevia and Ritchie, in preparation).

The results of these varied investigations leave no doubt that the decreases found in the present study are abnormal. Indeed, they are perhaps more striking in that the statistical analysis is based on workers who were not, in the main, complaining of symptoms sufficiently impressive to warrant a clinical diagnosis of asthma or bronchitis; in the reported studies of cotton workers a distinction has usually been drawn between byssinotic subjects, showing the more marked decreases in F.E.V..$_{1}$, and nonbyssinotic subjects. Whilst more information is required relating to weekly changes in other dusty occupations, it seems likely that the fall in ventilatory capacity is less transient in the isocyanate workers than in men with byssinosis. This accords with the clinical feature of nocturnal cough and dyspnoea in men affected by isocyanate: in the earlier stages, the symptoms of byssinosis occur during the day.

Effect of Bronchodilator Drugs.-The effects of an isoprenaline aerosol were equivocal. Even if it tended to reverse the decreases which had occurred on the Friday on which it was given, it did not reverse the change observed over the whole week. In a consecutive series of 50 mildly asthmatic subjects referred to this laboratory for routine assessment of ventilatory capacity, only two showed a decrease after isoprenaline, whereas a third of the present series did so. In guinea-pigs, an adrenaline aerosol is not completely effective in reversing bronchoconstriction induced by isocyanate (Friebel and Lüchtrath, 1955). By contrast, theophylline prevented a decrease in ventilatory capacity during a normal working day, preceded by a working day of minimal exposure and a week-end. It may be that a bronchodilator drug is more effective in preventing the decrease than in reversing an established one.

There is uncertainty as to the mechanism of the "asthmatic" reaction in men exposed to isocyanate. Some subjects appear to be allergic in that extremely minute concentrations may produce dramatic symptoms; in others, there is a genuine bronchitic component (Zapp, 1957; Holmqvist et al., 1953; Swensson et al., 1955). The present findings, supported by a more detailed study of both clinical and functional aspects of individual subjects, suggest that the factors involved in the increase in airways resistance are multiple and are not necessarily the same in all cases nor in the same subject at different times. 
Effects of Histamine Aerosol and Smoking.-A reduction of more than $10 \%$ in ventilatory capacity rarely occurs in normal subjects, whether smokers or not, on the administration of histamine aerosol in the strength used $(20 \mathrm{mg} . / \mathrm{ml}$.) (De Vries, 1961 ; personal observations). It is therefore remarkable that eight of 14 subjects with a negligible past history of bronchitis and asthma should be found to show bronchial hyperreactivity to histamine In view of the emphasis placed by Continental writers on "primary" bronchial hyperreactivity as a manifestation of an asthmatic tendency or diathesis (see, for example, De Vries et al., 1962), it is of interest that in the present series it is more likely to be a phenomenon acquired as a result of exposure to a bronchial irritant. The finding that all but one of the smokers studied gave a positive reaction to histamine, whereas none of the non-smokers did so, was unexpected. It implies, presumably, that two irritants are more likely to produce a state of bronchial hyperreactivity than one. The tendency for a greater mean fall in ventilatory capacity over a day in smokers is perhaps to be anticipated.

Relation of Isocyanate to Changes in Ventilatory Capacity.-No direct proof can be offered that isocyanate vapour caused the ventilatory changes and respiratory disability observed in workers in this factory, particularly as measurements of the isocyanate level in the air were not practicable at the time. A fortnight later, concentrations of 0.9 p.p.m. were found near the point at which the mix was sprayed on the conveyor belt.

The liberation of isocyanate during the manufacture of polyurethane foam is a well-recognized hazard. An excess of toluene di-isocyanate, one of the most toxic of the isocyanates because of its relative volatility, is used in the preparation of the mixture, and the manufacturer, an experienced chemist, had noticed its odour intermittently close to the mixture as it was being run. Odour implies a concentration above the maximum allowable concentration recommended by Zapp and by Sands and his colleagues (1957) of 0.1 p.p.m. (Strayer, 1959). Ventilation of the process and the factory generally was poor (the introduction of various precautions was one of the factors which made continuation of this study in its present form impossible) and a build-up of concentration or the development of pockets of high concentration over a day or even a week is quite feasible. The investigation itself shows a relation between decrease in ventilatory capacity and the process of "running the mixture". The functional studies tend to exonerate the other main process in the factory, that of sawing up the finished product. The dust liberated is relatively coarse and consists of chemically inert polymers; the contents of the individual foam cells are mostly monofluorodichlormethane, a relatively inert and non-toxic compound; the ventilatory tests do not suggest the presence of any irritant substance.

Finally, the clinical features of two severe and several mild cases of "bronchitis and asthma" seen personally, and the course of other known cases in the work force, have been consistent with the syndrome attributed to isocyanate inhalation, particularly, for example, in the severity and persistence of nocturnal cough.

This study was made possible by the expert technical assistance of Miss Nancy Rogers, to whom I am particularly indebted, and by the co-operation of the management and employees. My thanks are also due to Miss Betty Ferguson and Mrs. M. Hester, for secretarial assistance, and to Dr. A. Stiebris of the Industrial Hygiene Division, Department of Health, for the air analysis.

\section{REFERENCES}

Friebel, H., and Lüchtrath, H. (1955). Naunyn-Schmiedeberg's Arch. exp. Path. Pharmak., 227, 93.

Fuchs, S., and Valade, P. (1951). Arch. Mal. prof., 12, 191.

Gilson, J. C., Stott, H., Hopwood, B. E. C., Roach, S. A., McKerrow, C. B., and Schilling, R. S. F. (1962). Brit.J. industr. Med., 19, 9

Holmqvist, C-E., Lundgren, K-D., and Swensson, A. (1953). Svenske Läk.-Tidn., 50, 1839.

Lewinsohn, H. C., Capel, L. H., and Smart, J. (1960). Brit. med., J. 1,

462.
McKerrow, C. B., McDermott, M., Gilson, J. C., and Sshilling, R. S. F. (1958). Brit. J. industr. Med., 15, 75.

- and Schilling, R. S. F. (1961). J. Amer. med. Ass., 177, 850.

Perlman, E. (1960). Ann. Allergy, 18, 1350.

Reinl, W. (1953). Zbl. Arbeitsmed., 3, 103.

Sands, F. W., Boffardi, G., James, K. E., Lundy, W., and Walsh, W. S. (1957). Amer. industr. Hyg. Ass., Quart., 18, 331 .

Strayer, S. C. (1959). A.M.A. Arch. industr. Hlth. 19, 351

Swensson, A.., Holmqvist, C-E., and Lundgren, K-D. (1955). Brit. J. industr. Med., 12, 50.

Tiller, J. R., and Schilling, R. S. F. (1958). Trans. Ass. industr. med. offrs., 7, 161 .

De Vries, K. ', (1961). In Bronchitis: An International Symposium edited by N. G. M. Orie and H. J. Sluiter, p. 221. Royal VanGorcum, Assen, Netherlands.

Goei, J. T., Booy-Noord, H., and Orie, N. G. (1962). Int. Arch. Allergy, 20, 93 .

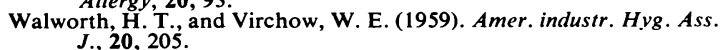

Zapp, J. A. (1957). A.M.A. Arch. industr. Hlth., 15, 324. 